\title{
Computational Study of Flow over Cascade Arrangement of Bluff Bodies with Different Geometries
}

\author{
Anurag Kumar \\ Assistant professor, \\ Mechanical Engineering, \\ Krishna Engineering College, \\ Ghaziabad, (UP) India, \\ Anurag.technologist@gmail.com
}

\author{
Sachendra \\ Assistant professor, \\ Mechanical Engineering, \\ Krishna Engineering College, \\ Ghaziabad, (UP) India, \\ sachendra43@gmail.com
}

\author{
Manish Singhal \\ Assistant professor, \\ Mechanical Engineering, \\ Krishna Engineering College, \\ Ghaziabad, (UP) India, \\ singhal.mech@gmail.com
}

\begin{abstract}
Most of the structures in flowing water are a challenge to their stability and sustainable with different flow conditions. Recent, renewable energy research and development covers ocean and river energy platform in which flow of water drag considered in various conversion devices towards the offshore and onshore establishment. Various energy platforms have been suggested for offshore development. However, the stability of these platforms in water is a serious concern. To study the water interaction over circular and square cross-section cascade system under the water has been carried out. Water flow around the pillars or column of the energy platform are analyzed through simulation software. Very low velocity $0.5 \mathrm{~m} / \mathrm{s}$ has been considered to analyze the system. Total fifteen numbers of cascade pillars having circular and square cross-section area were considered. $K-\varepsilon$ turbulence model is adopted to calculate the flow interaction to the column. A velocity, pressure, and energy fields are found around the column.
\end{abstract}

Keywords: bluff body; cascade, turbulence; ANSYS; and simulation; offshore energy platform

\section{INTRODUCTION}

Renewable energy captured $30 \%$ of the world market and further it is being developed in the various field. Current renewable energy generation is concentrated towards Solar, wind and marine energy conversion. The direct energy conversion from the renewable resources achieves through the available energy SPV system, wind turbine, and marine energy devices. To produce a significant amount of electricity through these devices require comparatively large area. As compared to solar energy wind energy are available majorly in the coastline. However, present research shows offshore wind technologies have been put into operation primarily in shallow waters using fixed-bottom foundations [1]. Previous investigations have shown that offshore wind turbines may require floating structures in deep waters instead of fixed-bottom foundations which are economically limited to a maximum water depth of $60 \mathrm{~m}$ [2].

The rapid growth of offshore renewable energy structures including offshore wind, solar and ocean energy devices (such as wave energy converters and tidal current turbines), the science, technology and innovative engineering in this field are phasing phenomenal changes of design and development. However, there is a lack of knowledge and competencies exist. This phenomenal growth is concentrated in particularly, for hybrid energy platforms, where wave, the wind, and solar platforms are combined to generate accumulated energy to cross over limitations of individuals.

There are a lot of research have been carried out in the last decades in the improvement and development of offshore energy platform structure. The stability of the energy platform over the water can be achieved via bed anchoring and multiple body platforms [3]. Karimi M., has proposed three types of pillars for wind turbine shown in Figure1. Six wind turbines platform study has shown comparison analyses of the different platform stability classes [4]. A comprehensive dynamic response for six floating offshore wind turbines (FOWTs), spanning all the stability classes, was presented by Robertson and Jonkman (2011). Lefebvre and Collu (2012) used seven preliminary platform concepts and compared them through a technoeconomic analysis to find the best design within the set of seven [5].

The Japanese electronics multinational Kyocera has begun work on what it says will be the world's biggest floating solar farm. The main challenge was to keep wiring away from the water and put the inverters - which convert the electricity generated into a usable form - on floating structures. But he added: "If anything goes wrong, I've always said electricity and water don't mix." [6].Offshore SPV system is majorly floating type to capture energy on the ocean surface. However, hybrid energy platforms require both floating types or anchored or moored type structure.

Offshore energy platform having various difficulties including majorly platform pillars (steel and concrete or rigid cables), transmission lines, stability from large waves and oceanic life interaction.

Present work shows the two types of platform pillars having circular and square cross-section 
considering cascade structure. The fluid interaction around the pillar has been shown with the help of ANSYS simulation. Velocity, pressure, and energy around the pillars have been calculated. The minimum fluid velocity $0.5 \mathrm{~m} / \mathrm{s}$ is considered.

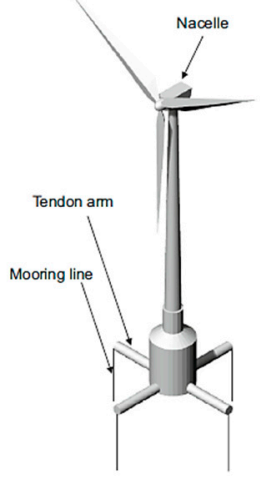

(a)

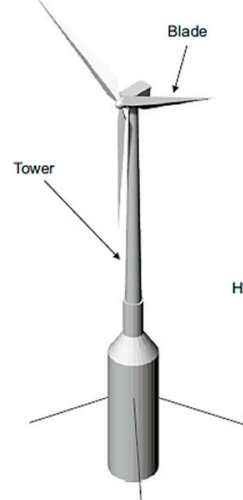

(b)

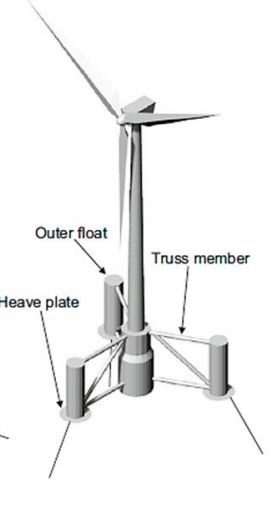

(c)
Fig. 1. The three classes of offshore floating wind turbine support platforms: a mooring stabilized (tension-leg), b ballast stabilized (spar buoy), and c buoyancy stabilized (semi-submersible) [3]

Total fifteen number pillar has considered to carry out the calculation of fluid behavior which interacts first, second, third, fourth and fifth rows of pillars. A closed contour with water inlet and outlet are considered which consist 15 circular and rectangular cross-section pillars of 1-meter height. This is similar to pillars under some depth of water such as energy platform pillars and oil rigs pillars. Thus similar profiles have been taken in cascade which may use in different energy structures under the water.

\section{GEOMETRY AND BOUNDARY CONDITIONS}

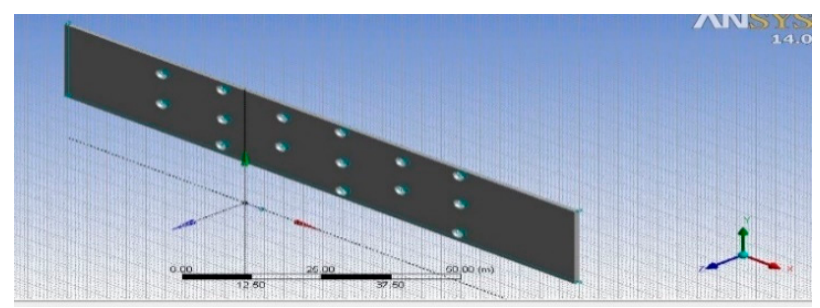

(a)

In Figure2, cascade circular cylindrical pillars geometry are shown and the mesh configuration and inlet, outlet and wall boundary represented. Mesh near the cylinder are tetrahedrons which create adequate calculations nodes for water behaviors on the pillars interactions.

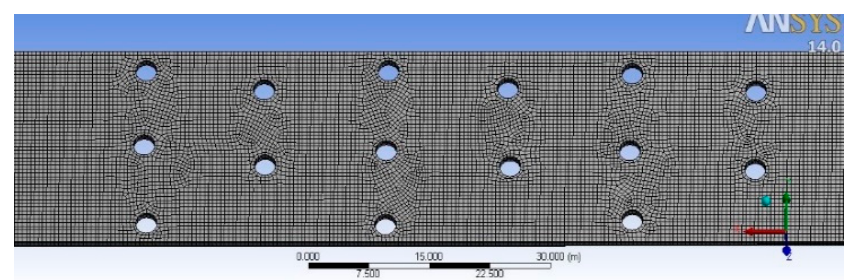

(b)

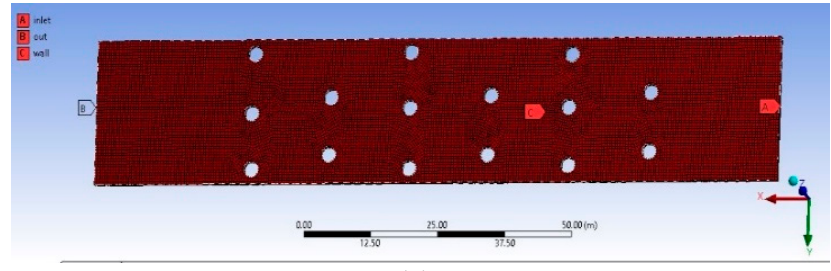

(c)

Fig. 2. Circular pillars (a) Geometry (b) Mesh and (c) boundary profiles.

A similar configuration for rectangular pillars is shown in the figure.

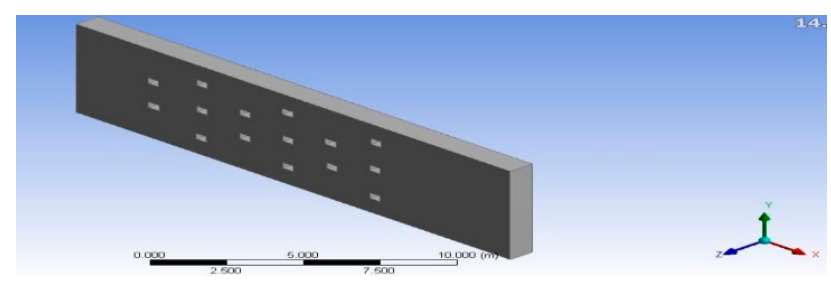

(a)

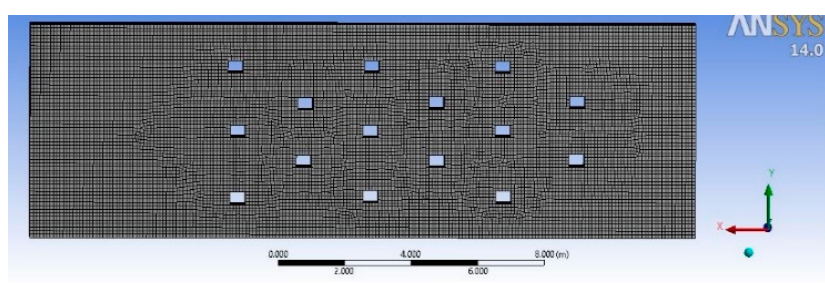

(b)

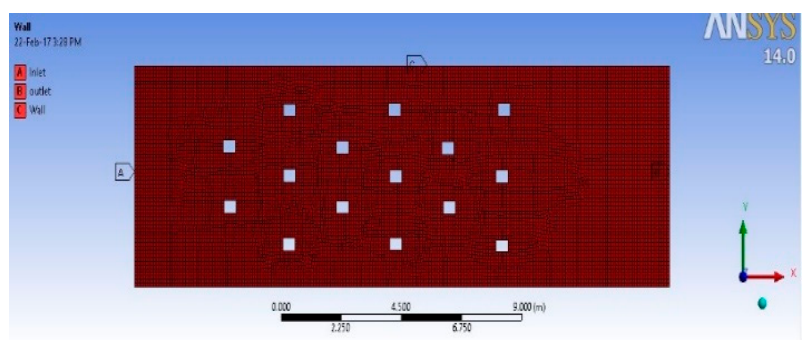

(c)

Fig. 3. Rectangular pillar (a) Geometry (b) Mesh and (c) boundary profiles.

The boundary conditions employed for the present investigation are (Figure 2 and 3 ) at the inlet, a uniform velocity has been prescribed $\mathrm{Uin}=0.5$ and $\mathrm{V}_{\text {in }}=$ 0.0 . at outflow, the condition was used which does not affect the flow in the upstream. To this end, the convective boundary conditions have been used. The confining boundaries (top and bottom) were modeled as the slip boundaries. No slip $(\mathrm{u}=\mathrm{v}=0)$ boundary conditions were used for the velocities on the obstacle surface. For this, a 0.3 Poisson ratio has taken to analyses wall shear stress near of the pillar surface. 


\section{GOVERNING METHODOLOGY \\ EQUATIONS}

AND

\section{A. The Mass Conservation Equation}

The equation for conservation of mass, or continuity equation, can be written as follows:

$\frac{\partial \rho}{\partial t}+\nabla \cdot(\rho \vec{v})=S_{m}$

Equation 1 is the general form of the mass conservation equation and is valid for incompressible as well as compressible flows. The source is the mass added to the continuous phase from the dispersed second phase (for example, due to vaporization of liquid droplets) and any user-defined sources.

For 2D axisymmetric geometries, the continuity equation is given by

$$
\frac{\partial \rho}{\partial t}+\frac{\partial}{\partial x}\left(\rho v_{x}\right)+\frac{\partial}{\partial r}\left(\rho v_{r}\right)+\frac{\rho v_{r}}{r}=S_{m}
$$

where $\mathrm{x}$ is axial coordinate, $\mathrm{r}$ is radial coordinate $\mathrm{V}_{\mathrm{x}}$ is axial velocity and $V_{r}$ is radial velocity.

\section{B. Momentum Conservation Equations}

Conservation of momentum in an inertial (nonaccelerating) reference frame is described by [7]

$$
\frac{\partial}{\partial t}(\rho \vec{v})+\nabla \cdot(\rho \vec{v} \vec{v})=-\nabla p+\nabla \cdot(\bar{\tau})+\rho \vec{g}+\vec{F}
$$

where $\mathrm{p}$ is the static pressure, $\overline{\bar{\tau}}$ is the stress tensor (described below), and $\rho \vec{g}$ and $\vec{F}$ are the gravitational body force and external body forces (for example, that arise from interaction with the dispersed phase), respectively. $\vec{F}$ also contains other model-dependent source terms such as porous-media and user-defined sources.

The stress tensor is $\overline{\bar{\tau}}$ given by

$\overline{\bar{\tau}}=\mu\left[\left(\nabla \vec{v}+\nabla \vec{v}^{T}\right)-\frac{2}{3} \nabla \cdot \vec{v} I\right]$

Where $\mu$ is the molecular viscosity, $I$ is the unit tensor, and the second term on the right-hand side is the effect of volume dilation.

For 2D axisymmetric geometries, the axial momentum conservation equations are given by

$$
\begin{aligned}
\frac{\partial}{\partial t}\left(\rho v_{x}\right)+\frac{1}{r} \frac{\partial}{\partial x}\left(r \rho v_{x} v_{x}\right)+\frac{1}{r} \frac{\partial}{\partial r}\left(r \rho v_{r} v_{x}\right)= & -\frac{\partial p}{\partial x} \\
& +\frac{1}{r} \frac{\partial}{\partial x}\left[r \mu\left(2 \frac{\partial v_{x}}{\partial x}-\frac{2}{3}(\nabla \cdot \vec{v})\right)\right] \\
& +\frac{1}{r} \frac{\partial}{\partial r}\left[r \mu\left(\frac{\partial v_{x}}{\partial r}+\frac{\partial v_{r}}{\partial x}\right)\right]+F_{x}
\end{aligned}
$$

The governing equations employed for LES are obtained by filtering the time-dependent Navier- Stokes equations in either Fourier (wave-number) space or configuration (physical) space. The filtering process effectively filters out the eddies whose scales are smaller than the filter width or grid spacing used in the computations. The resulting equations, therefore, govern the dynamics of large eddies. The LES capability in ANSYS Fluent is applicable to compressible and incompressible flows. For the sake of concise notation, however, the theory that follows begins with a discussion of incompressible flows. Filtering the continuity and momentum equations, one obtains

$$
\frac{\partial \rho}{\partial t}+\frac{\partial}{\partial x_{i}}\left(\rho \bar{u}_{i}\right)=0
$$

and

$$
\frac{\partial}{\partial t}\left(\rho \bar{u}_{i}\right)+\frac{\partial}{\partial x_{j}}\left(\rho \bar{u}_{i} \bar{u}_{j}\right)=\frac{\partial}{\partial x_{j}}\left(\sigma_{i j}\right)-\frac{\partial \bar{p}}{\partial x_{i}}-\frac{\partial \tau_{i j}}{\partial x_{j}}
$$

Where $\sigma_{i j}$ is the stress tensor due to molecular viscosity defined by

$$
\begin{aligned}
& \sigma_{i j} \equiv\left[\mu\left(\frac{\partial \bar{u}_{i}}{\partial x_{j}}+\frac{\partial \bar{u}_{j}}{\partial x_{i}}\right)\right]-\frac{2}{3} \mu \frac{\partial \bar{u}_{l}}{\partial x_{l}} \delta_{i j} \\
& \tau_{i j} \equiv \rho{\overline{u_{i} u_{j}}}-\rho \bar{u}_{i} \bar{u}_{j}
\end{aligned}
$$

And $\tau_{\mathrm{ij}}$ is the subgrid-scale stress defined by and $\tau_{\mathrm{ij}}$ is the subgrid-scale stress defined by

Filtering the energy equation, one obtains:

$\frac{\partial \rho \bar{h}_{s}}{\partial t}+\frac{\partial \rho \bar{u} \bar{u}_{h_{s}}}{\partial x_{i}}-\frac{\partial \bar{p}}{\partial t}-\bar{u}_{j} \frac{\partial \bar{p}}{\partial x_{i}}-\frac{\partial}{\partial x_{i}}\left(\lambda \frac{\partial \bar{T}}{\partial x_{i}}\right)=-\frac{\partial}{\partial x_{j}}[\underbrace{\rho\left(\overline{u_{i} h_{s}}-\overline{u_{i}} \overline{h_{s}}\right)}_{\text {subgrid enilhalpy flux }}]$

where $h_{s}$ and $\Lambda$ are the sensible enthalpy and thermal conductivity, respectively. The subgrid enthalpy flux term in the Equation is approximated using the gradient hypothesis

$$
\rho\left(\overline{u_{i} h_{s}}-\overline{u_{i}} \overline{h_{S}}\right)=-\frac{\mu_{\mathrm{SGS}} C_{p}}{\operatorname{Pr}_{\mathrm{SGS}}} \frac{\partial \bar{T}}{\partial x_{j}}
$$

Where $\mu_{S G S}$ is a subgrid viscosity, and $\operatorname{Pr}_{S G S}$ is a subgrid Prandtl number equal to 0.85 .

\section{Standard $k-\varepsilon$ Model}

Two equation turbulence models allow the determination of both, a turbulent length and time scale by solving two separate transport equations. The standard $\mathrm{k}-\varepsilon$ model in ANSYS Fluent falls within this class of models and has become the workhorse of practical engineering flow calculations in the time since it was proposed by Launder and Spalding [8]. Robustness, economy and reasonable accuracy for a wide range of turbulent flows explain its popularity in industrial flow and heat transfer simulations. It is a semi-empirical model, and the derivation of the model equations relies on phenomenological considerations and empiricism.

The standard k- $\varepsilon$ model [8] is a model based on model transport equations for the turbulence kinetic energy $(\mathrm{k})$ 
and its dissipation rate $(\varepsilon)$. The model transport equation for $k$ is derived from the exact equation, while the model transport equation for $\varepsilon$ _was obtained using physical reasoning and bears little resemblance to its mathematically exact counterpart. In the derivation of the $\mathrm{k}-\varepsilon$ model, the assumption is that the flow is fully turbulent, and the effects of molecular viscosity are negligible. The standard $\mathrm{k}-\varepsilon$ model is, therefore, valid only for fully turbulent flows. As the strengths and weaknesses of the standard $\mathrm{k}-\varepsilon$ model have become known, modifications have been introduced to improve its performance. Two of these variants are available in ANSYS Fluent: the RNG k- $\varepsilon$ model [9] and the realizable $k$ - $\varepsilon$ model [10].

The turbulence kinetic energy, $\mathrm{k}$, and its rate of dissipation, $\varepsilon$, are obtained from the following transport equations:

$\frac{\partial}{\partial t}(\rho k)+\frac{\partial}{\partial x_{i}}\left(\rho k u_{i}\right)=\frac{\partial}{\partial x_{j}}\left[\left(\mu+\frac{\mu_{t}}{\sigma_{k}}\right) \frac{\partial k}{\partial x_{j}}\right]+G_{k}+G_{b}-\rho \varepsilon-Y_{M}+S_{k}$

and

$\frac{\partial}{\partial t}(\rho \varepsilon)+\frac{\partial}{\partial x_{i}}\left(\rho \varepsilon u_{i}\right)=\frac{\partial}{\partial x_{j}}\left[\left(\mu+\frac{\mu_{f}}{\sigma_{\varepsilon}}\right) \frac{\partial \varepsilon}{\partial x_{j}}\right]+C_{1 \varepsilon} \frac{\varepsilon}{k}\left(G_{k}+C_{3 \varepsilon} G_{b}\right)-C_{2 \varepsilon} \rho \frac{\varepsilon^{2}}{k}+S_{\delta}$

In these equations, $G_{k}$ represents the generation of turbulence kinetic energy due to the mean velocity gradients, calculated as described in Modeling Turbulent Production in the $k-\varepsilon$ model. $G_{b}$ is the generation of turbulence kinetic energy due to buoyancy, calculated as described in Effects of Buoyancy on Turbulence in the $k$ $\varepsilon$ models. $\mathrm{Y}_{\mathrm{M}}$ represents the contribution of the fluctuating dilatation incompressible turbulence to the overall dissipation rate, calculated as described in Effects of Compressibility on Turbulence in the $k-\varepsilon$ models. $\mathrm{C}_{1 \varepsilon}, \mathrm{C}_{2 \varepsilon}$, and $C_{3 \varepsilon}$ are constants. $\sigma_{\mathrm{k}}$ and $\sigma_{\varepsilon}$ are the turbulent Prandtl numbers for $\mathrm{k}$ and $\varepsilon$ respectively. $\mathrm{S}_{\mathrm{k}}$ and $\mathrm{S}_{\varepsilon}$ are userdefined terms.

\section{RESULT AND DISCUSSION}

Simulation results are calculated in ANSYS Multiphysics solver platform. More than 500 hundred iterations are executed to converge equation for cylindrical pillar geometry and more than 1200 for rectangular cylinder geometry.

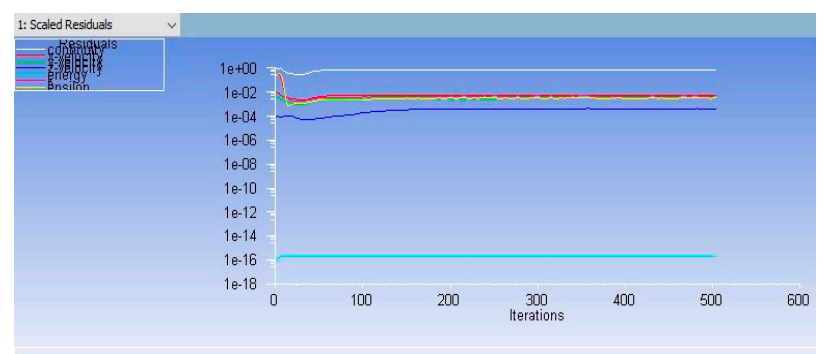

(a)

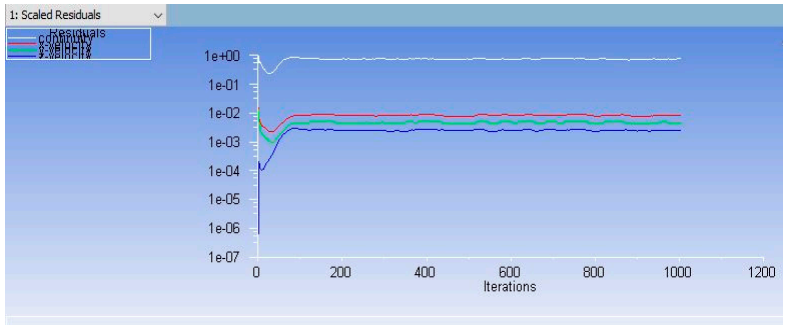

(b)

Fig. 4. Residual solution (a) Circular cylinder (b) rectangular cylinder

A velocity magnitude profile for circular cylinder and rectangular pillars are shown in Figure 5(a) and 5(b) respectively. As we can see the in Figure 5 both cascade profiles having velocity increase between the rows of the cylinder. However, velocity increase is greater in the circular cylinder than the rectangular cylinder. This is the result of higher wake developed around in circular cylinder. The velocity near the boundary of flow on either side of the channel considered is higher in the rectangular cylinder in comparison to the circular cylinder. This is due to narrow passage occurrence on either side of the channel.

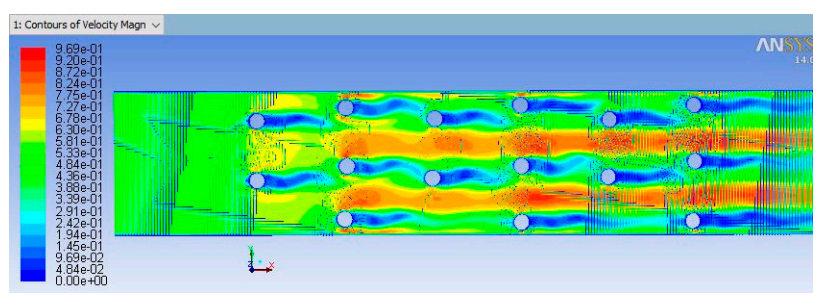

(a)

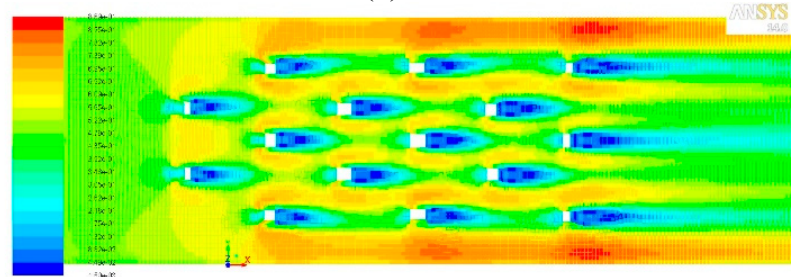

(b)

Fig. 5. Velocity magnitude in $\mathrm{x}$ direction for (a) cylindrical (b) rectangular cylinder

Figure 6 shows the velocity vectors near the cylinders, which represents circular wake profiles are well established in circular cylinder past as compared to rectangular cylinder past. From the Figure5. It is also cleared that the high velocity also occurs either side of the circular cylinder but this phenomenon not found in rectangular cylinders.

It is found that the velocity at the intercept on the front wall of cylinder reduces to a minimum. 


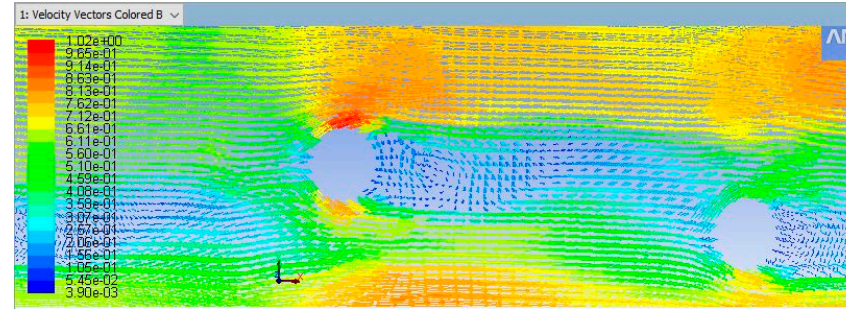

(a)

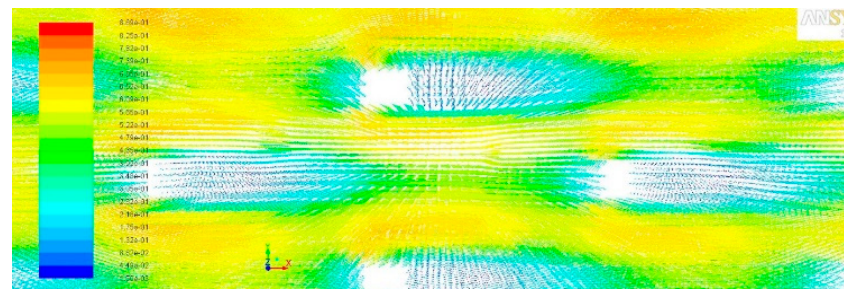

(b)

Fig. 6. Velocity vectors propagation in $\mathrm{x}$ and $\mathrm{y}$-direction (a) Circular Cylinder (b) rectangular cylinder

Static pressure distribution does reduce as cascading grows in both types of cylinders. However, the static pressure reduction occurs sharply in rectangle cylinders in comparison to circular cylinders and minimizes at the end.

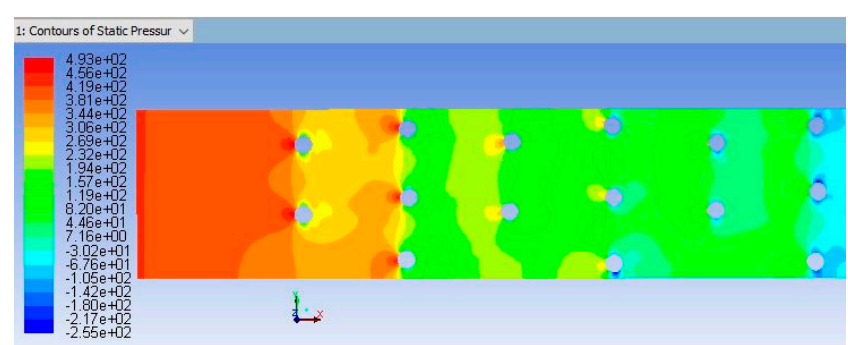

(a)
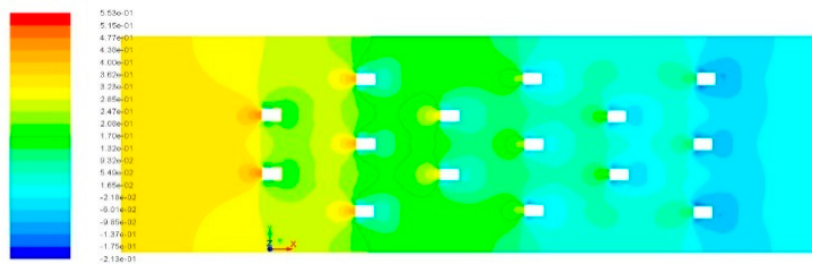

(b)

Fig. 7. Static pressure variation in cascade bodies (a) circular cylinder (b) rectangular cylinder

Which means, further cascading implies significant pressure reduction in flow. It is shown in Figure7.

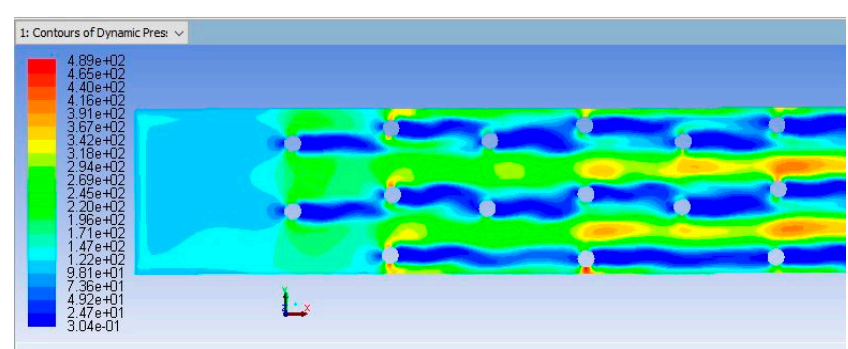

(a)
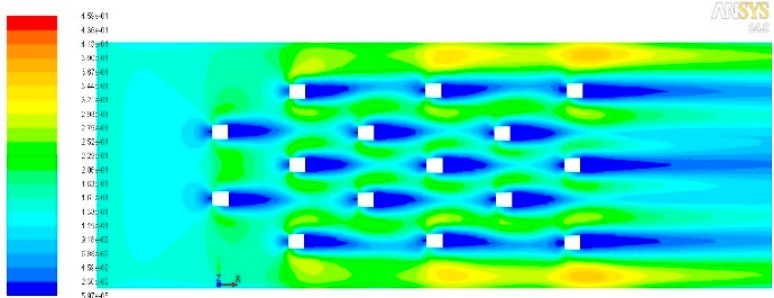

(b)

Fig. 8. Dynamic Pressure around flow past cascade bodies (a) Circular cylinder (b) Rectangular cylinder

Dynamic pressure spreading in flow reduced in great extent in the circular cylinder, at first attempt of water the circular cylinder act as pressure eater and water dynamic pressure does not overcome up to next cylinder. Figure8. shows dynamic pressure variations. Turbulence profile of the cascade cylinder is shown in Figure 9. which proves that the cascading of the circular cylinders in the flow does not produce a significant effect on the flow. However, in the case of rectangular cylinder turbulence intensity are highest at the entrance of the channel and lowest at the end of cascading.

Turbulence intensity is uniform after the fourth row of the cascading.

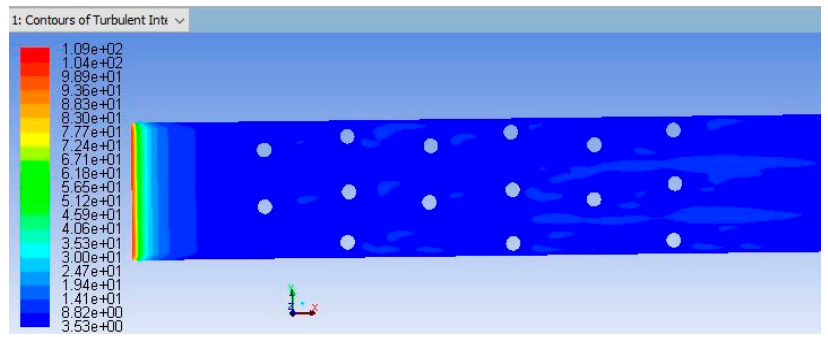

(a)

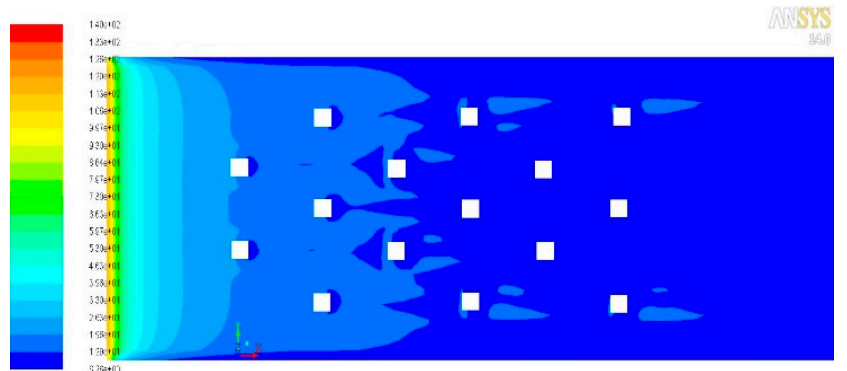

(b)

Fig. 9. Turbulence intensity of water around cascade bodies (a) Circular Cylinder (b) Rectangular Cylinder

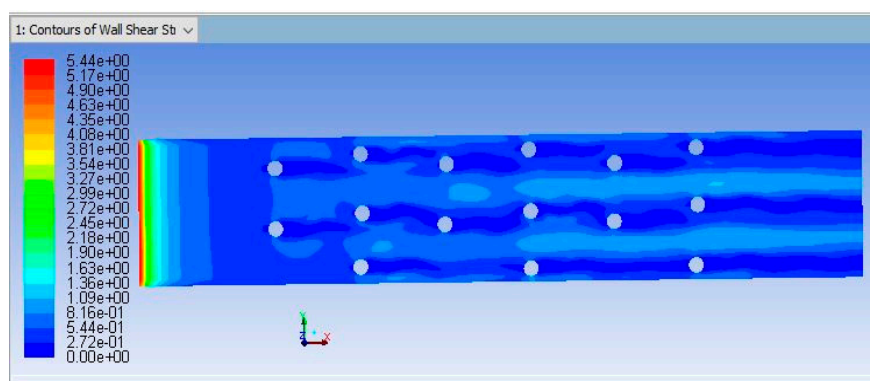

(a) 
Wall shear stress distribution are shown in Figure10. It is cleared from the Figure that wall shear stress is more significant on either side of the cylinder's side wall and less significant at the front of the wall.
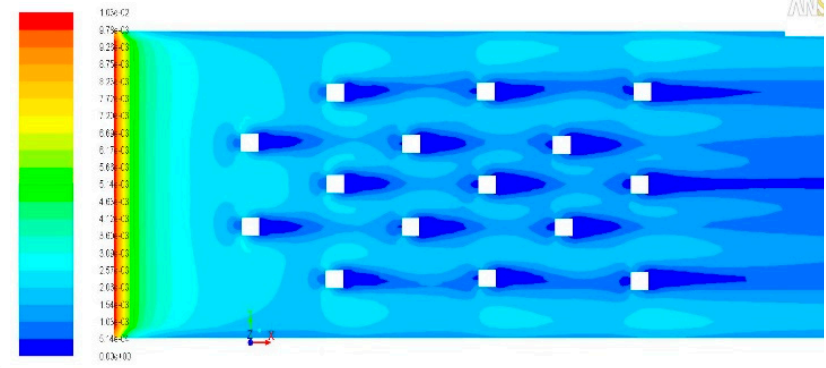

(b)
Fig. 10. Wall shear Stress distribution (a) Circular cylinders (b) Rectangular cylinders

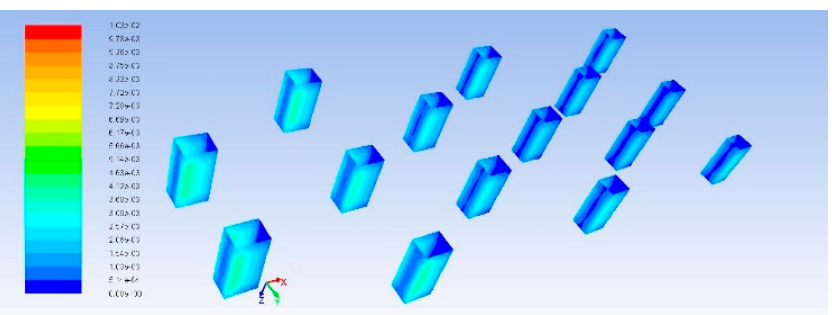

Fig. 11. Shear stress around the Rectangular cylinder wall at $0.5 \mathrm{~m} / \mathrm{s}$ velocity

However, it reduces to a minimum at the back side of the cylinder. The clear picture can be seen in Figure11 which shows separated cylinders from the water.

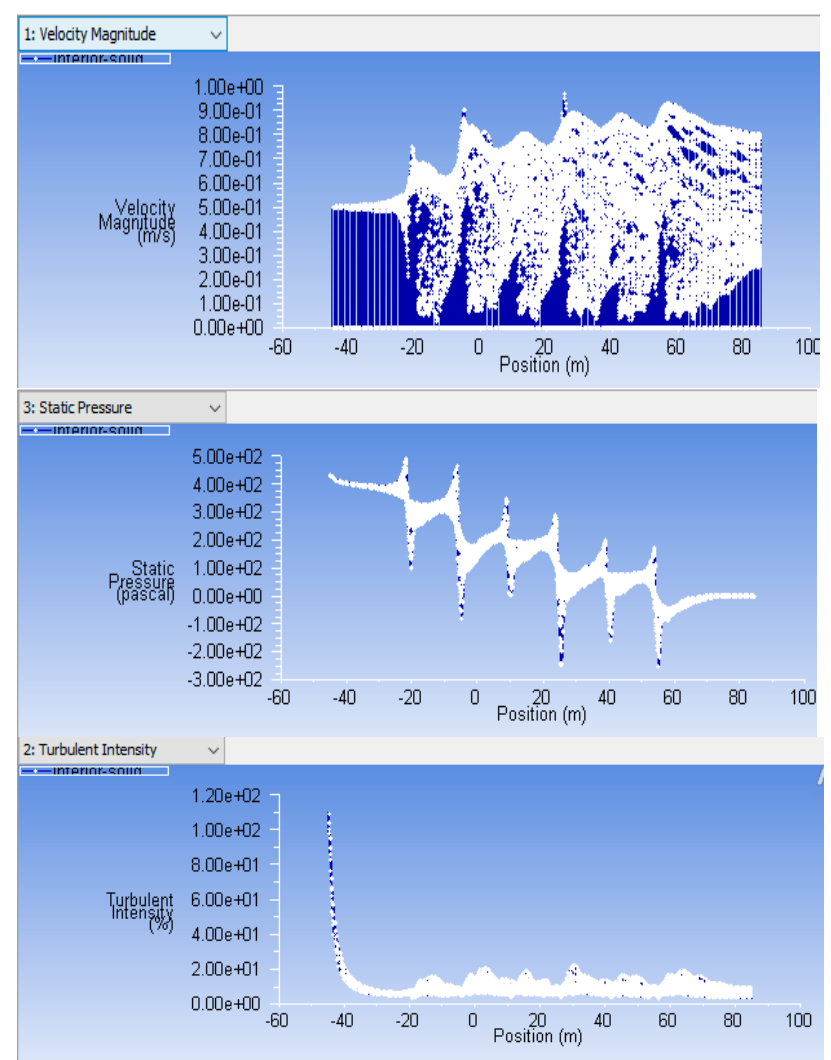

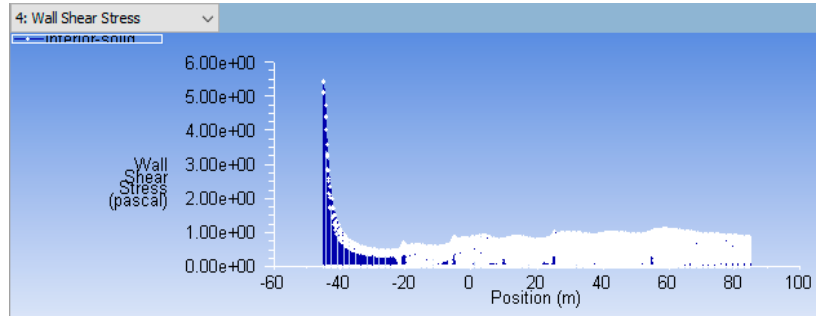

Fig. 12. Variation of flow Parameter of Circular cylinders in the calculation domain.

Flow properties are shown in Figure 12 and it represents, except the velocity, all other parameters are reduced in the direction of the $\mathrm{x}$-axis. However, the static pressure periodically increases as the cascading of cylinders occurs in rows.

\section{CONCLUSION}

Offshore energy platform is the future of the hybrid renewable energy generation which has many challenges in its innovations, design, and stability. However, current research scenario is involved in finding out the best solution for the research and analysis and also for the establishment of hybrid energy structures. The present research is carried out two types of cylinders circular and rectangular and it submerged fully the under the 1 meter of water depth. These cylinders are cascaded into the flow and effect of the flow over the cascade cylinder calculated. It is found that cascading of circular cylinders are more effectively increase the flow velocity either side of cylinders than the rectangular cylinder.

It is also found that the wall shear stress is more significant on either side of the cylinder's side wall and less significant at the front of the wall. However, it reduces to a minimum at the back side of the cylinder.

Further moving bluff bodies in the flow such as floating platform in cascading are suggested to be investigated.

\section{ACKNOWLEDGMENT}

The authors would like to acknowledge the Krishna Engineering College and Indian Renewable Energy Development Agency Limited (IREDA) for their support of their research data and reports accesses.

\section{REFERENCES}

[1]. Breton SP, Moe G (2009) Status, plans and technologies for offshore wind turbines in Europe and North America. Renew Energy 34(3):646-654.

[2]. Schwartz M, Himmler D, Haymes S, Musial W (2010) Assessment of offshore wind energy resources for the United States. Tech. rep, National Renewable Energy Laboratory (NREL), Golden, $\mathrm{CO}$

[3]. Karimi, M., Hall, M., Buckham, B. and Crawford, C., A multi-objective design optimization approach for floating offshore wind 
turbine support structures. Journal of Ocean Engineering and Marine Energy, pp.1-19.

[4]. Robertson A, Jonkman J (2011) Loads analysis of several offshore floating wind turbine concepts. Tech. rep, National Renewable Energy Laboratory (NREL), Golden, CO

[5]. Robertson A, Jonkman J, Masciola M, Song H, Goupee A, Coulling A, Luan C (2012) Definition of the semisubmersible floating system for phase ii of oc4. Tech. rep, National Renewable Energy Laboratory (NREL), Golden, CO

[6]. https://www.theguardian.com/environment/201 6/jan/27/japan-begins-work-on-worlds-largestfloating-solar-farm $<$ Accessed on $20 \mathrm{Feb} 2017>$

[7]. G. K. Batchelor. An Introduction to Fluid Dynamics. Cambridge Univ.Press. Cambridge, England. 1967.
[8]. B. E. Launder and D. B. Spalding. Lectures in Mathematical Models of Turbulence. Academic Press, London, England. 1972.

[9]. V. Yakhot and S. A. Orszag. "Renormalization Group Analysis of Turbulence I Basic Theory". Journal of Scientific Computing. 1(1). 1-51. 1986.

[10]. T.-H. Shih, W.W. Liou, A. Shabbir, Z. Yang, and J. Zhu. "A New k- $\varepsilon$ Eddy Viscosity Model for High Reynolds Number Turbulent Flows Model Development and Validation". Computers Fluids. 24(3). 227-238. 1995. 